Gema Gómez Rubio

gemma.gomez@uclm.es https://orcid.org/0000-0002-9008-7722 Universidad de Castilla-La Mancha

Antonia Ma Ortiz Ballesteros amaria.ortiz@uclm.es https://orcid.org/0000-0003-0322-7318 Universidad de Castilla-La Mancha

(Recibido: 1 julio 2021/ Received: $1^{\text {st }}$ July 2021) (Aceptado: 20 septiembre 2021 / Accepted: $20^{\text {th }}$ September 2021)

\section{DE ANCIANA AVARICIOSA A JOVEN EMPRENDEDORA: LA EVOLUCIÓN DEL PERSONAJE FEMENINO EN LAS REESCRITURAS INFANTILES DE LA LECHERA}

\author{
FROM AVARICIOUS OLD WOMAN TO YOUNG \\ ENTREPRENEUR: EVOLUTION OFFEMALE \\ CHARACTERS IN CHILDREN'S REWRITINGS OF THE \\ MILKMAID'S TALE
}

There are tales that are older than most countries, tales that have long outlasted the cultures and the buildings in whick they were first told" (Neil Gaiman, 2013).

\title{
Resumen
}

Este trabajo analiza nueve reelaboraciones de literatura infantil y juvenil actual en lengua castellana del conocido Cuento de la lechera (motivo ATU1430). Comienza con un breve repaso histórico que sistematiza las principales transformaciones sufridas en el proceso de transmisión cultural y muestra de qué modo las reescrituras actuales subvierten las versiones clásicas de La Fontaine y Samaniego. Posteriormente se examinan los textos seleccionados, a partir de la relación que mantienen con el hipotexto de referencia y según la técnica de reescritura empleada. El objetivo es señalar los cambios e innovaciones introducidos en el relato, que afectan particularmente a la caracterización y funcionalidad del personaje femenino y valorar su repercusión en la recepción del lector infantil actual. Se comprobará cómo la anciana avariciosa de los apólogos medievales (o a la jovencita frivola de las versiones clásicas) se convierte en un personaje creativo y emprendedor. Además, los nuevos textos se despojan del moralismo caracteristico de la fábula o subvierten los valores sociales con los que se habia asociado el relato tradicionalmente. El motivo, en suma, se reelabora y ofrece un concepto actualizado de la mujer y su papel social.

Palabras clave: Cuentística popular; Cuento de la lechera; Hipertextualidad; Técnicas de reescritura; Literatura infantil y juvenil.

\begin{abstract}
This work analyzes nine retellings of the well-known Milkmaid's folktale (motif ATU1430) in current children's and young people's literature in Spanish language. It begins with a brief historical review that systematizes the main transformations suffered in the process of cultural transmission and shows how the current rewritings subvert the classic versions of La Fontaine and Samaniego. Subsequently, the selected texts are examined considering the relationship they maintain with
\end{abstract}


the reference hypotext and the rewriting technique used. The aim is to point out the changes and innovations introduced in the story, which particularly affect the characterization and functionality of the female character so as to assess their impact on today's children's readers. It will be shown how the greedy old woman in medieval apologists (or the frivolous young girl in classic versions) becomes a creative and enterprising character. In addition, the new texts shed the fable's characteristic moralism or subvert the social values with which the story had traditionally been associated. In short, the motif is reworked and offers an updated concept of women and their social role.

Keywords: Folktales; Milkmaid's tale; Hypertextuality; Rewriting techniques; Children and young people literature.

\section{Introducción}

La lechera es un conocido cuento de origen folclórico, ligado a un motivo - ATU 1430 Castillos en el aire- cuyos orígenes parecen remontarse a la cultura popular india. Los caminos de la transmisión oral y escrita de este motivo no corren paralelos y se bifurcan con frecuencia, dibujando un mapa arbóreo del que solo podemos esbozar algunas ramas. En el caso del cuento de la lechera es precisamente el itinerario entrecortado de su difusión escrita el que, además de constatar su pervivencia, nos permite analizar las mutaciones sufridas por la protagonista en su paso a través de épocas y contextos diversos.

Ya algunos folcloristas y comparatistas de finales del siglo XIX (Müller, 1870; Millé, 1928) consideraron que la primera manifestación escrita conservada del relato era la incluida en el Libro $\mathrm{V}$ del Pantchatantra y podía remontarse a los siglos IV-III a C. Se trata de una recopilación de apólogos concebida para la educación moral, política y religiosa de los futuros gobernantes; de alli pasó, tras siglos de difusión, a otras colecciones orientales bien conocidas, entre las que destacan el Hitopadesa, el Kalila wa Dimna o las Mil y una noches (Müller, 1870; Millé, 1928). Estas manifestaciones orientales coinciden, entre otros ingredientes, en la presencia de un protagonista masculino de origen pobre (un brahmán, un ermitaño, un mendigo...), que fantasea con un cambio de estatus a partir de la venta de diversos productos (manteca, miel, harina, una liebre...); forma en que aún perdura en muestras literarias de distintas lenguas: chino, ruso, sueco, alemán, portugués, gallego...1

Las primeras versiones documentadas en Occidente conectan con esta tradición oriental gracias a la traducción del Kalila wa Dimna al latín y a otras lenguas romances (Millé, 1928; Fradejas, 2008:72) y se remontan al siglo XI. Están igualmente protagonizadas por un personaje masculino que pertenece a lo más bajo de la escala social (un indigente o religioso, según versiones), que planea vender la jarra de miel y manteca obtenida mendigando, hasta conseguir enriquecerse tras una sucesión de compra-ventas exitosas. El nuevo estatus imaginado permite al mendigo incluso vislumbrar su boda con una mujer noble con la que, a su vez, concebirá un hijo al que, con el tiempo, tendría que castigar por desobediente. Será precisamente el gesto que haga el personaje simulando

1 El alumno y las onzas de oro (Shiru y Calle, 1996, p. 70-71), El mujik y los pepinos de Tolstoi (Serrano, 2004: 97); Heinz el perezoso, de los hermanos Grimm (1996: 70-71); El chico y el zorro, de Djurklou (Ulwencreutz, 2015: 201); el Conto X de Fernandes Trancoso (1982, p. 43); O rapaz e maila lebre (Noia, 2010: 651-52)... Se trata en todos los casos de versiones que, pese a haber sido adaptadas o reelaboradas en diferentes épocas y lenguas, mantienen el protagonista masculino de origen humilde. 
golpear al hijo discolo² el que lo saque de la ensoñación y vuelque sobre su cabeza la jarra de miel y manteca en que habia puesto todas sus esperanzas.

Durante la Edad Media, los predicadores contribuyeron a difundir el relato por el territorio europeo, incorporándolo a las colecciones de exempla o al repertorio de anécdotas habituales de sus sermones. En este contexto se han documentado las primeras versiones protagonizadas por una mujer: el número LI de los Sermones vulgares de Jacques de Vitry (h. 1165-1240) alude a una anciana avariciosa - vetulla la denomina de forma despectiva el autor- que proyecta hacerse rica con las ganancias que le dará la venta de un jarro de leche; también Etiènne de Bourbon intercala, en fechas muy próximas (h. 1180-1286), una anécdota similar entre los exempla que ilustran las consecuencias de la conducta vanidosa en sus Anecdotes historiques. Légendes et apologues (números 265-272); asimismo, en la literatura peninsular es muy conocido el ejemplo del cuento VII de El conde Lucanor (1335), protagonizado por doña Truana, otra anciana avariciosa que acaba perdiendo la miel por exceso de ambición. Entre todos estos ejemplos medievales ${ }^{3}$, destaca la versión incluida en los Dialogus creaturarum (1481) de Nicolás de Pérgamo por ser una de las más difundidas en el continente europeo ${ }^{4}$; frente a la anciana de sus predecesores, el protagonismo recae por vez primera sobre una joven criada que, además de soñar con enriquecerse, aspira a mejorar su estatus a través del matrimonio con un noble, pretensión que lleva al autor a alertar contra la avaricia y la vanidad de ciertas mujeres. Se trata, según se intuye, de reescrituras donde el cambio de sexo del protagonista se debe a la actitud misógina de muchos predicadores en la época (Cátedra, 1986: 43).

A partir del siglo XV se documentan en diversas lenguas europeas versiones del apólogo que introducen ciertos toques de humor y diluyen la carga doctrinal (Fradejas, 2008: 146), lo que dirige la crítica explícita de la avaricia u otros pecados hacia la burla o escarnio motivados por la ingenuidad o insensatez de los personajes que levantan castillos en el aire, como en el caso de la protagonista del Auto de Mofina Mendes de Gil Vicente (1534, vv. 450-493), el matrimonio del paso Las aceitunas de Lope de Rueda (1548) o el personaje principal del cuento 49 del Portacuentos de Timoneda (1564). Es precisamente en el siglo XVI, cuando Bonaventure Des Périers, en su colección de cuentos Nouvelles rècréations et joyeux devis (Lyon, 1558), dará a conocer en una de estas versiones (más próxima a la facecia que al apólogo) a una mujer ingenua que ve frustradas sus fantasías y servirá de modelo a Jean de La Fontaine, un siglo después, para componer La laitiere et le pot au lait, dentro de sus famosas Fables choisies mises en vers (París, 1668).

Respecto a las versiones anteriores, la protagonista de La Fontaine aparece individualizada con un nombre (Perrette), va ataviada con un vestido corto y ligero, muestra una actitud confiada e ingenua $y$, según se deduce del comentario final del narrador, está casada y teme los probables reproches del marido tras su imprudencia. A esta caracterización del personaje, añade el fabulista francés una extensa moraleja en la que muestra su condescendencia con la protagonista y disculpa sus fantasias como conducta propia de la condición humana:

2 El personaje castigado cambia de género con su paso al árabe, pues en las versiones del Panchatantra y el Hitopadesa, el religioso castigaba a la supuesta esposa y no al hijo aún no nacido.

3 El objetivo y los límites de este trabajo nos impiden detenernos en todos los ejemplos recopilados hasta la fecha. Para ampliar el corpus mencionado en esta introducción pueden consultarse los trabajos de Fradejas (2008) o Gómez Rubio y Ortiz Ballesteros (2015).

4 La anécdota que nos interesa se incluye en el diálogo número 100. Entre otros logros, el Dialogus creaturarum fue la primera obra impresa en Suecia en 1481 y alcanzó gran popularidad y difusión en el norte de Europa (Noruega, Suecia, Dinamarca). 
Quel esprit ne bat la compagne?

Qui ne fait châteaux en Espagne?

Pichrocole, Pyrrhus, la Laitière, enfin tous;

Autant les sages que les fous! (La Fontaine, 1768: 23)

La reescritura de La Fontaine supuso un punto de inflexión en la difusión y popularidad del relato. La lechera y el cántaro de leche pasa por ser, después de La cigarra y la hormiga, la fábula del autor que más se traduce al castellano (Ozaeta, 2001: 167) y tuvo también enorme repercusión en autores de otras lenguas europeas: Gleim en Alemania, Mandeville en Inglaterra, Pignotti en Italia, Krylov en Rusia o Samaniego en España realizarán versiones, más o menos próximas al hipotexto, protagonizadas por una joven de similares caracteristicas.

Por lo que se refiere a la versión más difundida en lengua castellana, La lechera de Samaniego (1781), ofrece numerosas innovaciones frente a su predecesor: así, el autor prescinde del nombre propio que individualizaba a la protagonista, pero, en contrapartida, profundiza en su caracterización psicológica desde el inicio de la fábula, destacando la satisfacción vital de la muchacha y la ausencia de necesidades materiales, algo que contrasta con la tradición enraizada en el Calila. Por otro lado, Samaniego se aleja del tono condescendiente de La Fontaine y refuerza el carácter prescriptivo de la moraleja final introduciendo un triple imperativo: "Modera tu alegria", "no seas ambiciosa", "no anheles, impaciente, el bien futuro" (Samaniego, 2003, vv. 39, 43, 47), lo que no deja dudas sobre su actitud reprobatoria.

Aunque la fábula del autor alavés tuvo un éxito inmediato y se convirtió en texto de referencia del canon escolar hispánico, la versión de La Fontaine se siguió traduciendo y adaptando en nuestra lengua, con lo que ambas reescrituras sirvieron como modelo a autores posteriores y comparten en la actualidad un lugar destacado en el repertorio clásico.

A partir de las últimas décadas de la pasada centuria, con la llegada de la democracia y el reconocimiento creciente de la LIJ como modalidad independiente en el ámbito hispánico, surgieron nuevas recreaciones de fábulas y cuentos tradicionales dirigidos a la infancia y la juventud. Jaime García Padrino (2018) destaca, en la década de los setenta y los ochenta, un renovado interés de los autores por los cuentos y los materiales tradicionales, que se manifiesta tanto en los numerosos trabajos de recopilación folclórica como en un intento de revalorización de dichos materiales, expresados como "recreación preocupada por realzar el carácter oral de las historias" o "actualización crítica de elementos característicos de la literatura popular" (Garcia Padrino, 2018: 235). En este nuevo contexto encontramos las primeras reelaboraciones contemporáneas de La lechera, que partirán de alguno de los dos hipotextos mencionados e incorporarán transformaciones relativas, principalmente, a la caracterización y función de la protagonista femenina, hasta depararle un desenlace aparentemente más halagüeño. En este sentido, nuestro trabajo contribuye a mostrar el significado de estos cambios, en la línea abierta por numerosos investigadores sobre las reescrituras de cuentos populares (Bacchilega, 1997, Cascajosa, 2005; McAra, 2011; Ferreira, 2012; Piña, 2013; Pérez Parejo, 2015; Jerez y Hernández, 2015, etc.), y a valorar las repercusiones de estos en el receptor infantojuventil. Para ello nos serviremos de un corpus de textos representativos de la narrativa infantil española contemporánea. 


\section{Método}

\subsection{Selección de la muestra}

Dado que el número de reelaboraciones es bastante elevado, para el análisis hemos establecido un corpus constituido por aquellas muestras que introducen cambios significativos para la interpretación de su sentido general, es decir, que se alejan de la lectura tradicional o canónica de la fábula. Dicha desviación suele anunciarse en el título, o en alguno de los paratextos de la obra, con expresiones del tipo "nueva fábula de...", "la otra fábula de..." o "fábula del revés." Se descartan, por tanto, las traducciones y adaptaciones directas de La Fontaine o Samaniego consistentes únicamente en la prosificación y simplificación del hipotexto y carentes, por ello, de innovaciones o modificaciones que afecten al sentido general del cuento, como podría ser La lechera y el cántaro de Beatriz Barnes (1989). Asimismo, solo se han tenido en cuenta reescrituras publicadas en el ámbito hispánico posteriores a 1975.

Tras aplicar estos criterios, se han seleccionado nueve versiones infantiles que se presentan a continuación, ordenadas cronológicamente por el año de su primera edición:

1976. Las fantasías de la lechera, texto de Fernando Alonso ilustrado por José Navarro; publicado por primera vez en la colección "Serie B" de la editorial Santillana.

1979. "La lechera fabulista", de Empar de Lanuza Hurtado, con ilustraciones de Montserrat Ginesta. El relato aparece incluido en el volumen El sabio rey loco y otros cuentos (pp. 65-70), una colección de narraciones infantiles publicada por La Galera galardonada con el premio Josep M. Folch i Torres en 1978.

1988. La otra fábula de: La lechera, escrita e ilustrada por Miguel Ángel Pacheco, ganador del Premio Nacional de ilustración en 1980, y publicada por primera vez en 1988 por la editorial Montena.

2006. "El cuento de la lechera" de Alberto Szpunberg; ilustrado por Sergio Kern e incluido en Fábulas. Leer, jugar y aprender, publicado por Editorial Sol 90.

2006. "El cuento de la lechera", de Victor González y Pablo Amargo (il); incluido en El río que se secaba los jueves y otros cuentos imposibles (pp. 83-85), publicado originalmente por la editorial Anaya y reeditado recientemente por Kalandraka (2020).

2007. La nueva lechera, de Carmen Contreras González, M. Rosario Rodríguez Parra e Isabel M. ${ }^{a}$ Contreras González, publicado por la editorial GEU en la colección "Cuentos para comprender: programa de lenguaje para atención a la diversidad".

2008. "La lechera", de Teresa Durán y María Espluga (il.), incluido en Cuéntame un cuento de animales, (pp. 70-79) una recopilación de fábulas publicada en 2008 por la editorial Planeta bajo el sello Timun Mas Infantil.

2008. "Tercera aventura. Donde se narra el casual encuentro del caballero Florianis con la soñadora lechera, la conversación que ambos mantuvieron y la feliz idea que puso fin a las desdichas de aquella", en Los cuentos del abuelo Florián (o cuatro fábulas del revés), (pp. 33-46), de Norma Huidobro; ilustrado por M. ${ }^{a}$ Fe Quesada; obtuvo el IV Premio Leer es vivir de Everest en 2008.

2011. "La niña que vendia leche", texto de Edgar Allan García e ilustraciones de Roger Ycaza, incluido en Fábulas vueltas a contar (pp. 89-94), publicadas por la editorial Santillana Ecuador en 2011.

Es de notar que tres de las versiones se publicaron como obras independientes en formato de libro ilustrado: Las fantasías de la lechera, de F. Alonso; La otra fábula de la lechera, de M. Á. 
Pacheco y La nueva lechera, de Carmen Contreras; en ellas, tanto las ilustraciones de portada como los títulos hacen una referencia explícita al personaje universalmente conocido, pero añaden además al título alguna otra palabra que advierte de su "novedad", como se ha comentado. De los seis títulos restantes, cuatro forman parte de una recopilación de relatos que, a veces, ni los propios editores son coherentes a la hora de etiquetar, por lo que usan indistintamente la denominación de fábula o cuento en el mismo volumen ${ }^{5}$. Respecto a los textos de Norma Huidobro y Teresa Durán, se presentan como capítulos enmarcados dentro de una narración mayor que unifica y cohesiona los diversos episodios que conforman la trama.

\subsection{Análisis y resultados}

El análisis de estos textos se ha realizado atendiendo, por un lado, a la relación textual que las nuevas versiones establecen con el hipotexto ${ }^{6}$, asi como al tono e intencionalidad de los autores a la hora de reescribir la historia; por otro, a las diferencias que afectan a los elementos narrativos de las versiones actuales frente a las clásicas: contextualización o planteamiento, caracterización de la protagonista - peculiaridades, expectativas, lo que motiva la pérdida del producto- desenlace, presencia o no de una segunda oportunidad y la presencia o no de moraleja. Para lo primero, tomamos como referencia la teoría sobre la transtextualidad de Genette (1989), así como los trabajos precedentes de Millé (1928), Fradejas (2008), Gómez \& Ortiz (2015) sobre el devenir del relato que nos ocupa; para lo segundo, recurrimos a una sistematización propia de los elementos narrativos que permiten oponer las versiones actuales frente a las clásicas.

\subsubsection{Presencia del hipotexto y relación con el hipertexto}

La presencia del hipotexto es explícita en Las fantasias de la lechera de F. Alonso En este relato pueden distinguirse dos partes diferenciadas: la primera sintetiza, sin saltar episodios, el cuento tradicional; en la segunda se produce una expansión en la que se reproduce una situación idéntica que, esta vez, concluye con un desenlace feliz. También La otra fábula de la lechera de M. Á. Pacheco incluye el hipotexto de referencia, la fábula de Samaniego, si bien no forma parte de la reescritura, sino que aparece al final, a modo de apéndice, con la posible intención de que el lector pueda comparar (conozca o no el relato tradicional) ambas versiones. Se indica: "Félix María de Samaniego nos contó esta fábula asi", tras lo cual está presente la moraleja, el texto y la fecha de publicación del texto base. La voluntad de preservar el relato tradicional también se muestra en la contracubierta del libro, al advertir:

Estas son las fábulas de siempre contadas de otra forma, desenfadada y optimista, pero sin perder nada de su clásico sabor. Con todos los elementos didácticos que las hicieron inmortales, pero con unas gotas de esperanzado humor, de poética fantasía que las vuelve más accesibles a los niños actuales. (Pacheco, 1988, contrac.)

5 Es el caso de "El cuento de la lechera" de A. Szpunberg, incluido en un volumen titulado Fábulas o de Los cuentos del abuelo Florián, de N. Huidobro, que lleva por subtitulo Cuatro fábulas del revés. Por su parte, el título de "La lechera fabulista", de Empar de Lanuza, también anticipa una transformación respecto al texto base que cobrará sentido en el desenlace del relato.

6 Consideramos hipotexto o texto-base, indistintamente, a cualquiera de las versiones canónicas de La Fontaine o Samaniego; el empleo de este término y de otros asociados como hipertexto, trasposición, trasformación, pastiche, parodia, etc., sigue la terminología propuesta por Genette (1989). 
Distinto es el caso de "El cuento de la lechera" de Víctor González, quien no ofrece el relato base pero lo da por conocido: "La lechera iba camino del mercado, con el consabido cántaro de leche en precario equilibrio sobre su cabeza. Este principio es bien conocido7." (González, 2006: 83). El planteamiento sigue según la tradición, con pocos cambios, hasta el momento del tropiezo, en el que se aparta del relato clásico, pues la protagonista no pierde su producto:

Sin embargo, la lechera, abstraída en sus pensamientos, tropezó con un tejón que cruzaba por alli y casi se le cae el cántaro al suelo. Por suerte eso no ocurrió, pero a partir de ese momento dejó de darle a cabeza y fue mucho más atenta al camino. (González, 2006, p. 83)

A diferencia de las anteriores, en las restantes reescrituras el hipotexto es reconocible pero no está explícito. Así, en Los cuentos del abuelo Florián, Huidobro pone en boca de la protagonista los elementos básicos del hipotexto de referencia (una lechera que pierde su producto por soñadora) como arranque del relato, incluyendo ya nuevos detalles:

Una apacible tarde de primavera, caminaba distraído el joven Florianís por la orilla del arroyo, cuando un estruendo de platos rotos lo sacó de su divagar. Miró a un lado y a otro hasta que descubrió, no muy lejos de donde estaba, a una joven sentada en el suelo, junto a un charco de leche y un cántaro hecho añicos. Rápidamente fue el caballero a su encuentro, pensando que la chica podría necesitar ayuda:

- ¡Ay, qué mala suerte tengo! — se lamentaba la pobre, sin levantarse del piso.

- ¿Por qué se queja de su suerte, señora? - le preguntó Florianís mientras se sentaba a su lado.

- ¿Cómo no voy a quejarme? Mire este charco de leche. Iba al mercado a venderla y se me rompió el cántaro... y ... ibuaaa...! — se largó a llorar la desdichada.

- Eso no es nada grave-dijo Florianís, intentando consolarla-. Compre otro cántaro y la próxima vez que vaya al mercado tenga más cuidado.

-Sí... pe... pero... no ... es la pri... primera vez que... que ... me pa... pasa..._tartamudeó la lechera con la voz tembleque, porque no es fácil hablar y llorar al mismo tiempo. (Huidobro, 2008: 34-36)

De igual modo, las restantes reescrituras establecen relaciones con el hipotexto de manera diversa pero sin mencionarlo expresamente. Esto implica que las conexiones que establezca el lector serán diferentes dependiendo de su nivel de conocimiento del relato tradicional. Adicionalmente a esta relación más o menos directa y explícita con el hipotexto principal de referencia, todas las reescrituras contienen pistas o marcas intertextuales que permiten a los jóvenes lectores activar su intertexto lector (Mendoza, 1996) por vincularse a otros hipotextos, leídos o reconocibles. Así, en la primera parte de La lechera fabulista, de Empar de Lanuza, la protagonista es una niña que debe realizar un itinerario-reto, tanto físico como personal, en el que se encuentra con algunas figuras; las analogías con Caperucita Roja resultan evidentes. Algo parecido sucede con las menciones a El Ratoncito Pérez, Las zapatillas rojas o con el imaginario típico de los cuentos de hadas (por ejemplo,

$7 \quad$ Las cursivas son nuestras. 
el bosque lleno de obstáculos que debe atravesar la protagonista) que se incorpora al cuento de Szpunberg. Elementos característicos del cuento maravilloso se encuentran en La otra fábula de la lechera, de Pacheco, donde una bruja transformada en serpiente convence a la lechera para ir a un castillo donde se casará con un príncipe, mientras que en la versión de Teresa Durán son elementos procedentes de otras fábulas populares, igualmente reconocibles por los jóvenes lectores; así, durante el camino que recorre su lechera, esta va recordando "sucesos tan emocionantes" como la carrera de la liebre y la tortuga o lo que le sucedió a Pedro con el lobo (Durán, 2008: 72).

En definitiva, existe variedad en las relaciones de los nuevos textos con el hipotexto clásico, así como las técnicas y estrategias textuales con que los autores reelaboran el sentido de la fábula tradicional. De ellas nos ocuparemos más detenidamente en el siguiente epígrafe, si bien todas coinciden en cambiar el desenlace del relato clásico y otorgar a la protagonista una segunda oportunidad, lo que le permite la reparación de la pérdida sufrida, como sucede en las expansiones realizadas por F. Alonso, M. Á. Pacheco y N. Huidobro. En otras ocasiones no hay continuación, sino modificación del desenlace conocido, que forma parte del desarrollo y genera un final alternativo para el relato, tal como muestran los relatos de Empar de Lanuza, donde la "lechera" se convierte en cuentacuentos para conseguir el éxito.

Todo ello contribuye, fundamentalmente, a crear expectativas en un joven lector que, desde los primeros cambios presupone posibles alternativas al final tradicional —si conoce este- 0 - si no es así-genera también hipótesis a partir de las pistas textuales, sus lecturas previas, conocimientos e interés personal. Por otro lado, implica la transformación de los constituyentes del relato. Ateniéndonos a la terminología empleada por Genette, según el alcance de las transformaciones a partir de la consabida combinación de la intención (lúdica, satírica, seria) y la relación entre hipotexto e hipertexto (acercamiento a apartamiento), estaremos ante imitaciones serias transposiciones, pastiches o transformaciones paródicas.

\subsubsection{Imitaciones serias}

En esta primera categoría podemos incluir Las fantasías de la lechera de Alonso, La nueva lechera de Carmen Contreras y La niña que vendía leche de Edgar Allan Garcia, en las que se crea una nueva versión muy próxima al hipotexto, aunque se ofrezca un final alternativo en los dos primeros casos y se expanda o complemente la historia, en el último.

Además de ser la más antigua, Las fantasias de la lechera (1976), de Fernando Alonso, es también la reescritura más sencilla. Apenas se distancia del hipotexto en su primera parte pero incluye, tras la pérdida de la leche, una continuación en que se permite a la protagonista (una lechera joven y pobre que trabaja para un granjero muy rico) cumplir sus sueños. No obstante, para ello es necesaria la intervención del granjero que, gracias al tesón y buen trabajo de la joven, le regala un segundo cántaro de leche y, con él, una nueva oportunidad para que sus planes se hagan realidad.

Esta versión se relaciona a un tiempo con las de Samaniego y La Fontaine: el planteamiento y caracterización de la protagonista recuerdan al primero, al tratarse de una joven innominada de la que solo conocemos su origen humilde y su carácter laborioso (Alonso, 1976, p. 3), mientras que la relación de subordinación o dependencia entre la joven y el granjero conecta más con el segundo y, a través de él, con la versión tradicional, pues el cántaro que el granjero regala a la lechera parece una reminiscencia de la limosna recibida por el antiguo protagonista del relato. Esto hace que, pese a la transformación del desenlace funesto en final feliz, los valores tradicionales ligados a la visión masculina del mundo sigan muy presentes en el relato, así como en las ilustraciones que lo 
acompañan; en este sentido, son llamativos en el desenlace los cuatro hombres que, tras un muro, ponen imagen a la admiración que la protagonista ha conseguido generar de manera unánime: "Y todo el mundo admiraba/ los hermosos animales/ que la lechera criaba" (Alonso, 1976: 16).

Por su parte, la versión de Carmen Contreras presenta en común con la de Alonso que imita la versión tradicional hasta el momento del "tropiezo" y añade una expansión que dirige la narración hacia un desenlace feliz. La autora prescinde de cualquier planteamiento previo, como en las versiones originales, y el relato comienza in medias res, justo en el momento en que la lechera (de la que no se precisa nombre, edad ni otras peculiaridades físicas) se dirige "muy contenta" a vender la leche al pueblo. Están ausentes otros personajes en la trama, con lo que desaparece la presencia masculina y su función "facilitadora". La expansión del relato supone una inversión de valores respecto al hipotexto: bajo la piedra que la hace tropezar, la lechera encuentra una bolsa de monedas de oro que la ayuda a cumplir sus deseos sin necesidad de vender la leche: "y así la lechera aprendió que no siempre chocar con piedras en el camino era tan malo" (Contreras, 2007:13). Sin embargo, a este comentario en consonancia con el nuevo desenlace, se añade una moraleja explícita que coincide parcialmente con la tradicional y recupera un imperativo en segunda persona que recuerda la versión de Samaniego, lo cual puede parecer contradictoria: "Si tus sueños quieres realizar, primero debes despertar" (Contreras, 2007: 13).

Otra pieza que puede catalogarse igualmente como imitación seria con expansión del desenlace es la de Edgar García (2011), si bien en esta ocasión se aprecia una mayor transformación respecto al hipotexto que en las versiones precedentes. El autor ofrece en el título y el planteamiento los detalles mínimos necesarios para que los lectores asocien esta nueva versión con el relato tradicional, pero enmarca la trama en un contexto urbano y en unas coordenadas espaciotemporales contemporáneas. En este caso la protagonista es una niña de unos nueve o diez años -tampoco sabemos su nombreque se presenta en su entorno familiar cotidiano. Después del colegio, la muchacha contribuye a la

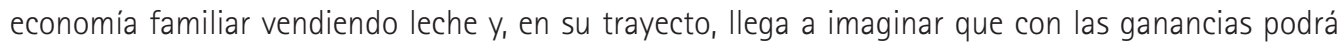
comprarse un vestido para ir a las fiestas del barrio y ser la envidia de todos. La pérdida de la leche se produce de la forma esperada, por un descuido, cuando tropieza con una piedra en el camino, pero en la expansión del cuento se deja la "reprimenda" en manos de la madre, que anima a la niña a reflexionar sobre lo aprendido a partir de tan mala experiencia:

- ¿Qué pasó con los tarros de leche?

- Se me cayeron- dijo ella, entre sollozos.

- ¿Y por qué se te cayeron?

- Porque iba pensando en lo que haría cuando vendiera la leche-gimoteó la niña.

- Su madre la sentó sobre sus piernas y le dijo:

- ¿Qué fue lo que aprendiste hoy?

- La niña se quedó pensando un instante y entonces respondió:

-Que no debo distraerme, que debo concentrarme en lo que estoy haciendo.

- De acuerdo- comentó la mamá-, pero tal vez hayas aprendido otra cosa.

- La niña dejó de llorar y dijo:

-No sé qué más aprendi, mami.

- No importa - dijo la mamá, y le pidió que fuera a jugar con sus hermanas.

-Al poco rato, volvió la niña. (García, 2011: 90-92) 
Se produce entonces una maduración personal que lleva a la pequeña a conformarse con lo que tiene y no presumir de ello para provocar envidia: "no les dijo a sus amigos que tenía la mejor mamá del mundo porque esta vez no quería que los demás le envidiaran semejante regalo de la vida" (García, 2011: 93). Esta versión se cierra con una doble moraleja explícita: es preciso reflexionar sobre los errores para no repetirlos y no está bien querer provocar la envidia de otros.

Un elemento Ilamativo de la reescritura de Edgar Garcia es el protagonismo femenino compartido entre madre e hija. La juventud de la lechera justifica la existencia de una figura de autoridad que la anime a reflexionar sobre su accidentada experiencia antes de imponerle una lección explícita. Juntas, aparentemente, dirigen la interpretación del receptor: "no está mal hacer planes, no está mal querer comprarse algo bonito", [...] "pero tal vez no debí desear que me envidiaran. Con solo comprar el vestido habría sido suficiente" (García, 2011: 92). Por tanto, el cuento propone un modelo de madre dialogante y reflexiva, que encarna los valores de lo políticamente correcto vigentes en la actualidad, frente a un modelo de hija ingenua, obediente y algo superficial (es presumida y desea ser admirada). Con ello, lo que era originariamente un apólogo contra los castillos en el aire, se convierte en un relato contra la vanidad y los deseos de ser envidiada en función de la apariencia y el accidente que frustra los sueños de la niña parece necesario para su aprendizaje.

\subsubsection{Trasposiciones}

Aunque también se trata de una reescritura seria, la forma en que se distancia del texto base permite la clasificación de La lechera fabulista, de Empar de Lanuza (1979), como una trasposición en la que se transforman totalmente los elementos del relato a excepción de aquellos imprescindibles para identificar el texto de partida: la presencia del personaje que va a vender leche al pueblo con intención de sacar el máximo rendimiento posible y la pérdida de la mercancía antes de llegar al destino.

En este caso la protagonista es María, una niña de 12 años que decide ir a vender la leche por voluntad propia, para mostrar a sus padres que es mayor y puede contribuir a la economía familiar. De ahí que sus "cuentas" durante el trayecto al pueblo vayan dirigidas a conseguir el máximo beneficio posible para la familia y no solo para ella. En este caso, la pérdida de la leche no se produce por un descuido o un exceso de alegría, sino por generosidad: a lo largo del camino la joven va encontrando a diferentes animales hambrientos que le piden ayuda y ella les da leche hasta quedarse sin producto:

Asustada vio que ya casi no quedaba leche en los cubos: solo habia dos dedos en cada uno:

— ¿Qué haré? ¿Qué haré? —-se decía preocupada- He regalado la leche que tenía que vender. ¿Cómo voy a volver a casa sin leche y sin dinero? No me dejarán venir nunca más...

Y la pobre Maria se acercaba cada vez más al pueblo donde debía vender la leche que no tenía. Caminaba despacio, mirando el suelo. Ya no sonreía, ya no pensaba si debía vender la leche a quince o a dieciocho... En su cabeza solo había una idea: "¿Cómo venderé la leche si no la tengo? ¿Cómo ganaré el dinero que he de dar a mis padres?". (Lanuza, 1979: 69)

Frente a las versiones clásicas, donde la excesiva imaginación del personaje ocasionaba la pérdida del producto y era, por tanto, algo negativo y censurable, en esta versión lo aparentemente negativo se convierte en positivo y salva a la protagonista:

- ¡Ya está! ¡No puedo perder tiempo!

Y, apresurándose, llegó a la plaza del pueblo. Cuando llegó allí gritó con voz fuerte: 
- ¡Señoras, señores, ha llegado la lechera!

Y cuando la gente se le acercó a comprar dijo:

- Hace muchos años había una lechera que cuando iba a vender la leche se encontró por el camino una liebre, una ardilla y un jabalí...

Y asi, paso a paso, contó todo cuanto le había pasado como si fuera un cuento. La gente escuchaba con la boca abierta. (Lanuza, 1979: 69)

De esta forma, la protagonista decide cambiar de profesión - una solución que encontraremos también en la versión de Huidobro- para ser cuentacuentos, lo que implica un cambio de sentido total respecto al hipotexto.

Atendiendo a la originalidad del planteamiento narrativo y al resultado formal, la de Empar de Lanuza figura entre las versiones más interesantes de las analizadas, pues se ofrece, pese a ser de las más antiguas, un personaje femenino que rompe el estereotipo tradicional e introduce una perspectiva actual. Se añaden otros logros en la caracterización de la protagonista: la chica vive en un entorno familiar rural en el que todos los miembros desempeñan una función similar, sin que se establezcan entre ellos roles estereotipados en función del género, pues ambos padres se comportan, además, de igual modo, como si fueran un personaje único. A esto se añade que, a pesar de su edad, es una adolescente responsable, generosa y con iniciativa, que no se hunde ante las dificultades y sabe salir de ellas airosa gracias a su actitud positiva y al uso de la imaginación. Tampoco sus deseos están determinados por estereotipos o actitudes codificadas tradicionalmente como masculinas o femeninas, pues solo quiere desarrollar bien su nueva responsabilidad y no defraudar a sus padres. No hay, por tanto, alusiones o juicios sobre su apariencia o aspecto físico y únicamente en el planteamiento se incluye una mención puntual a su ropa: "se puso su mejor vestido y se caló el sombrero de paja" (Lanuza, 1979: 65). La única ilustración de la joven que aparece junto al texto se aleja también de las descripciones tópicas de la lechera inspiradas en La Fontaine o Samaniego y se aproxima a la ternura e ingenuidad que facilite la identificación con los posibles lectores.

\subsubsection{Pastiches, collage y ensaladas}

Un tercer tipo de reescritura se ofrece en La otra fábula de la lechera (1988) de Miguel Ángel Pacheco, El cuento de la lechera (2006) de A. Szpunberg y el capítulo dedicado a "La lechera" en Cuéntame un cuento de animales de Teresa Durán y María Espluga. Estamos ante imitaciones lúdicas que podemos denominar pastiches, collage o ensalada, en los que más allá de cambiar o expandir únicamente el desenlace, se desarrollan y transforman igualmente otros episodios de la historia insertando elementos que proceden de otros cuentos o fábulas y son fácilmente reconocibles para el lector.

En este sentido, la versión de Pacheco parte del planteamiento clásico del conflicto, con una joven y anónima lechera de camino al mercado, pero dilata el episodio de las "cuentas" incorporando dos ingredientes de interés: la protagonista considera que las ganancias dependerán de la situación del mercado (a menor oferta y menos lecheros, más ganancias para la joven) y de la participación de otros miembros de la familia en el negocio (el padre y la madre también podrian acompañarla a vender leche al mercado), con lo que se trasciende el individualismo tradicional de la fábula y se introduce una dimensión familiar o social que extiende las repercusiones del negocio a otras personas, algo ya presente en la versión de Empar de Lanuza y que reaparecerá en posteriores reelaboraciones. Con ello, se convierte a la protagonista en una joven decidida, responsable, preocupada por su familia y con visión comercial: su sueño consiste únicamente en ampliar el negocio, algo que, sin embargo, 
no evita el tropiezo ni el derramamiento posterior de leche. A partir del desgraciado momento, lo que parecía un relato "realista" da un giro sorprendente y se convierte en un cuento maravilloso, con la aparición de una serpiente parlante:

Lloraba desesperada pensando qué les diría a sus padres cuando de la maleza surgió una enorme serpiente que se bebió la leche derramada por el suelo y la que aún quedaba en los restos del cántaro, esparcidos aquí y allá.

Acto seguido, para asombro de nuestra lechera, la serpiente se puso a hablar:

- Gracias por el desayuno querida niña-le dijo- debes saber que no soy una serpiente cualquiera sino la reina de todas ellas, pues en realidad soy el hada Morgana, transformada por el astuto Merlín, príncipe de los encantadores...

Y deseo concederte un premio, no solo por alimentarme tan generosamente, sino porque adoro a las criaturas con fantasía y espíritu comercial.

No vayas al mercado de la aldea, puesto que ya nada tendrias que hacer alli, más bien dirígete al palacio real donde te aguarda una sorpresa- - dicho esto se perdió en la espesura de donde había salido. (Pacheco, 1988: 20-22)

En el palacio, la lechera es recibida por los reyes y el príncipe heredero, con quien acabará casándose. Un breve epilogo final añade que ambos fueron felices haciendo quesos, pero se prescinde de toda moraleja explícita o implícita. Por tanto, el relato se despoja en su segunda parte del carácter fabulístico e incorpora las convenciones e ingredientes típicos del cuento de hadas, estereotipos de género incluidos.

Del mismo modo, también El cuento de la lechera (2006) de Szpunberg introduce ingredientes fantásticos típicos del cuento maravilloso que expanden el episodio del camino y demoran el desenlace feliz de la historia. Aunque la protagonista exclusiva es Emma, una joven trabajadora, cuidadosa e imaginativa que vive con su familia en el pueblo, se recurre en la segunda parte a la inclusión de dos personajes masculinos antitéticos: el alcalde, que reprende a la joven por dejarse embaucar por los sueños, y un joven poeta que comparte con ella la facilidad para dejarse llevar por la fantasía. El joven y Emma se enamoran, se casan y abren juntos una lechería mágica que hace feliz a otros, gracias a que venden productos que tienen el poder de hacer realidad los sueños.

La versión incluida por Durán en Cuéntame un cuento de animales puede catalogarse asimismo como imitación lúdica basada en la técnica del pastiche o la ensalada de fábulas y recurre a algunos ingredientes que ya estaban en Szpunberg (el personaje del alcalde que alecciona a la protagonista y la intertextualidad con otros cuentos tradicionales a lo largo del camino al mercado). En este caso, la autora reúne y reelabora una serie de fábulas tradicionales en torno a Fabulén, el país de las fábulas, un espacio ficcional en el que se unifican e integran relatos de diversa procedencia y en el que conviven y se relacionan los personajes protagonistas de algunas fábulas populares: así, la joven lechera Rita es hermana del pastor Pedro, protagonista de Pedro y el lobo, hija del granjero Blas, propietario de La gallina de los huevos de oro y vecina de personajes como la cigarra, la hormiga, la tortuga o la liebre. Al frente de todos los habitantes de Fabulén está el alcalde (el señor Lechuza), que intenta mantener la convivencia y resolver los conflictos que se plantean. En lo referente al personaje que nos interesa, la lechera se presenta una vez más como una chica que siempre tiene la cabeza en las nubes (Durán, 2008: 71), aunque ahora asistimos a un cambio de planteamiento, ya que la joven tiene que desplazarse diariamente hasta el pueblo porque su tarea consiste en proporcionar 
la leche del desayuno o la cena al resto de habitantes de Fabulén. En este caso, sus ensoñaciones y planes de futuro durante el trayecto no se explican tanto por un deseo de enriquecerse para vivir holgadamente en el futuro como por la necesidad de cambiar su monótona vida y que le sucedan cosas tan emocionantes como las vividas por su padre con la gallina de los huevos de oro o por la tortuga que ganó la carrera a la liebre. El resultado de sus sueños, no obstante, acaba siendo la pérdida de la leche, con las consecuencias negativas que ello tiene para sus planes y para la dieta de sus vecinos; de ahi que tenga que intervenir el alcalde, figura autoritaria que introduce la moraleja explícita en un largo parlamento con que aconseja a la joven dejar de soñar y centrarse en su tarea:

-Ay, Rita!- quiere consolarla el alcalde señor Lechuza-. Nunca sueñes con un mañana que no tenga los cimientos bien colocados en el día de hoy. Valía más la leche que llevabas en la jarra que todas las aventuras que soñabas por el camino. Si hubieras mirado dónde pisabas y hubieras estado por la tarea de hoy, en vez de tener la cabeza pesando en lo que harías mañana, la jarra no se habría roto, la leche no se habría vertido y tú ahora tendrías tus polluelos. Recuerda que más vale pájaro en mano que ciento volando. (Durán, 2008: 76)

No obstante, a pesar de esta "reprimenda" al estilo de La Fontaine, Rita reemprende el camino al pueblo al día siguiente soñando con "alguien que algún día escriba sus desventuras" para que algún lector arriesgado, quizá "algún niño como tú, que fuera hijo del emperador de la China o príncipe de las galaxias", quisiera ir a Fabulén a conocerla (Durán, 2008: 77).

\subsubsection{Parodias}

El último grupo de transformaciones pertenecen a lo que se denomina transformación paródica, pues subvierten el sentido del relato de partida con intención lúdica, como sucede en el relato de Norma Huidobro, o, incluso, satírica, en el texto de Víctor González en El río que se secaba los jueves, quien, siguiendo la estela de Dahl (1988), Rodari (1993) o Garner (1995) reinterpreta la historia en clave postmoderna. El autor recurre para ello a una caracterización hiperbólica de la protagonista, una mujer adulta llamada Esmeralda que cuenta con una fuerza sobrehumana y mucha suerte. Es la única lechera que no pierde la mercancía y consigue ganar más dinero del imaginado a partir de una rara ocurrencia: poner a la leche un precio más caro del habitual. A través de la protagonista, se burla el autor del funcionamiento del mercado y quienes pagan sumas desorbitadas por productos comunes que consideran exclusivos y únicos:

En cuanto estuvo instalada en el mercado empezó a vender la leche. Aunque no tenía conocimientos de marketing ni sabía nada de fluctuaciones del mercado, oferta, demanda y todo eso, tuvo la rara ocurrencia de ponerla a la leche un precio exageradamente alto: cien euros por litro. Sus otras colegas lecheras comentaban:

—Esmeralda está loca. ¿Quién va a pagar esa barbaridad por un litro de leche? Nadie.

Pero ella no hizo caso y se limitó a esperar confiadamente. Cuando la gente llegaba a su puesto y veía el precio de la leche se decía:

-Esa leche tiene que ser extraordinaria. De otro modo no podría valer tanto.

Y todos compraban al menos un cuartillo, aunque solo fuera para probarla. Se corrió la voz. Algunos millonarios caprichosos le compraron cientos de litros [...]. (González, 2006: 84) 
Con el dinero de estos ingenuos, la lechera monta una moderna y gigantesca instalación agropecuaria que le permite retirarse y vivir feliz en Saint Tropez hasta el fin de sus días (González, 2006: 84-85), por lo que el desenlace acaba subvirtiendo los valores del relato tradicional. El tono irónico y la intención satírica del autor es evidente desde la primera oración del relato: "el cuento de la lechera es un magnífico ejemplo de tesón, superación personal y autoconfianza" (González, 2006: 83), que anticipa la moraleja e invierte el sentido de la versión de partida, y se mantiene hasta el final gracias a las hipérboles y a los ingredientes insólitos que el narrador introduce en el desarrollo de la acción, pero también a través de la constante autorreferencialidad del relato, puesto que la voz narrativa se introduce en la historia, dirige la atención del lector y subraya las diferencias de la nueva versión respecto a la tradicional.

Como en el caso anterior, hay un uso de la parodia y la caricatura del personaje tradicional en Los cuentos del abuelo Florián, de Norma Huidobro (2008), una reescritura de cuatro "fábulas al revés" que se engloban, como episodios independientes, en una narración marco protagonizada por el caballero don Florianis. Este personaje quijotesco ayuda a los protagonistas de diversas fábulas tradicionales a "resolver" sus conflictos de forma insólita. En el capítulo inspirado en la fábula de la lechera, la autora prescinde del planteamiento tradicional y hace que el lector se incorpore a la trama, junto al personaje de don Florianís, una vez que el cántaro se ha roto y la protagonista llora desconsolada y exageradamente, según ya se ha indicado. En medio de esa situación, es la propia lechera quien narra sus desdichas al caballero Florianis y acaba haciendo de sí misma un retrato que raya lo caricaturesco, pues se trata de una chica soñadora y obstinada que, a pesar del fracaso continuo, hace una y otra vez el mismo camino con la leche al mercado con la esperanza de tener éxito algún día, comportamiento que le ha granjeado el sobrenombre de "loca del cántaro" entre quienes la rodean. La solución al problema en este caso también se produce de forma insólita y gracias al ingenio de la protagonista, aunque a través de la mediación involuntaria de don Florianís, que empatiza con ella y se describe igualmente como un "soñador incurable". La lechera repara en que los caramelos de dulce de leche que el caballero le ha dado para consolarla no pueden derramarse, por lo que decide cambiar de actividad y tomar estos como producto para vender; así pues, reformula sus planes a partir de una nueva mercancia, sin necesidad de cambiar de actitud ni renunciar a su forma de ser. A partir de aqui, el final queda abierto, pues no sabemos el éxito que tendrá esta nueva empresa, y sin moraleja explícita:

Y los dos se dieron la mano como si acaban de concretar un gran negocio. De este modo, y por simple casualidad, intervino el caballero en la solución de los problemas de la lechera (de aqui en más, caramelera), que en el futuro pudo vender la leche en el mercado convertida en caramelos, sin dejar de soñar por el camino. (Huidobro, 2008: 46)

Estamos, pues, ante nueva una reescritura paródica en la que predomina una intención fundamentalmente lúdica, aunque se invierten igualmente los valores tradicionales y el personaje femenino sale reforzado; de hecho, logra sus sueños que no son otros que "poder soñar", en contra de las pretensiones materiales de las lecheras clásicas. No hay, por lo tanto, ningún tipo de moraleja que censure un comportamiento que a nadie perjudica ya. 


\section{Conclusiones}

Las reescrituras infantiles y juveniles analizadas remiten indistintamente a las versiones clásicas de La Fontaine o Samaniego y mantienen el planteamiento y el protagonismo femenino del relato, si bien varia la edad de las protagonistas y su entorno: hay niñas y jóvenes que conviven con sus familias o mujeres adultas que se ganan la vida trabajando para otros o para si mismas.

Sin embargo, a pesar de conservarse la caracterización profesional como lechera y la necesidad de vender su producto como nexo para el reconocimiento del hipotexto por parte del receptor, los cambios son de calado y conducen a una nueva interpretación del mensaje y también de la historia, en la línea con la relectura de los cuentos populares que se está produciendo en las últimas décadas y, particularmente, en lo que se refiere a los estereotipos.

Excepto en una ocasión, se mantiene constante la pérdida del producto tal y como sucede en las versiones clásicas, sea por causas involuntarias (un tropiezo o por exceso de alegria) o expresamente asumidas por la protagonista, como en el caso de la generosidad de la niña en La lechera fabulista. No obstante, lejos de terminar con los sueños de la muchacha, la pérdida abre paso siempre a una segunda oportunidad que permite a la protagonista madurar y alcanzar sus sueños, sea cambiando de profesión, encontrando al amor de su vida o valorando aquello que posee; de ahí que los relatos presenten una estructura clara en dos partes: una que imita fielmente al hipotexto con escasas modificaciones, y otra que implica el cumplimiento de los sueños; en este sentido, el episodio de la caída o la pérdida de la leche funciona como una especie de bisagra entre ambas fases.

La presencia masculina es variable: el marido severo de Perrette al que alude La Fontaine no va más allá del texto del fabulista francés y se sustituye, cuando se trata de ejercer la autoridad de quien debe reprender para educar, por la madre u otras figuras sociales, como el alcalde de Fabulén. Al margen de este último ejemplo, los personajes masculinos que aparecen desempeñan un papel secundario, aunque en algunas versiones, aparezcan como facilitadores (don Florianis, el granjero, los millonarios engañados) o como objeto de deseo de la protagonista (un novio, un marido).

En general, se observa un distanciamiento del género fabulístico a favor del cuento, con lo que se evitan las moralejas y el adoctrinamiento y se propicia que el receptor extraiga su propio aprendizaje. En suma, se presenta a una mujer que, de una forma u otra, no se conforma con la desgracia ni se lamenta, sino que supera las dificultades y es capaz de convertirse en la dueña de su negocio, de su destino y de quienes conviven con ella.

\section{REFERENCIAS BIBLIOGRÁFICAS}

Alonso, F. \& Navarro, J. (1976). Las fantasías de la lechera. Santillana.

Bacchilega, C. (1997). Postmodern fairy tales: Gender and narrative strategies. University of Pennsilvania Press.

Barnes, B. (1989). La lechera y el cántaro. II. Marta Gaspar. SEP-Cuentos de Polidoro.

Cascajosa, C. C. (2005). Caperucita en el guetto: Freeway, de Matthew Bright, como adaptación posmoderna de un cuento de hadas. Espéculo. Revista de estudios universitarios, (29), 5-7. https://webs. ucm.es/info/especulo/numero29/ freewayc.html.

Cátedra, P. (1986). La mujer en el sermón medieval (a través de los textos españoles). En: La condición de la mujer en la Edad Media (pp. 39-50). Casa de Velázquez-Editorial de la Universidad Complutense.

Contreras González, M. C. (2007). La nueva lechera. Editorial GEU. 
Dahl, R. (1988). Cuentos en verso para niños perversos. Altea.

Durán, T. Et Espluga, M. (il.) (2008). Cuéntame un cuento de animales. Planeta-Timun Mas Infantil.

Fernandes Troncoso, G. (1982). Contos e histórias de proveito e exemplo. Biblioteca Nacional de Lisboa.

Ferreira Boo, C. (2012). La reescritura de brujas y princesas en la Literatura Infantil y Juvenil gallega del siglo XXI. AILIJAnuario de Investigación en Literatura Infantil y Juvenil (10), 47-56. https:// revistas.webs.uvigo.es/index.php/AILIJ/ article/view/886.

Fradejas Lebrero, J. (2008). Más de mil y un cuentos del Siglo de Oro. IberoamericanaVervuert.

Gaiman, N. (15/10/2013). Why our future depends on libraries, reading and daydreaming. The guardian. https://www.theguardian. com/books/2013/oct/15/neil-gaimanfuture-libraries-reading-daydreaming

García Padrino, J. (2018). Historia crítica de la Literatura Infantil y Juvenil en la España actual (1939-2015). Marcial Pons.

Garcia, E. A. (2011). Fábulas vueltas a contar. Santillana: Loqueleo.

Garner, J. F. (1995). Cuentos infantiles políticamente correctos. Circe.

Genette, G. (1989). Palimpsestos. La literatura en segundo grado. Taurus.

Grimm, J. \& W. (1986). Cuentos de niños y del hogar, III. Traducción y apéndice de M. A. Seijo. Anaya.

Gómez Rubio, G. \&t Ortiz Ballesteros, A. M. ${ }^{a}$ (2015). Nuevos castillos en el aire (AT 1430): lecturas y reescrituras del cuento de la lechera y algunas nuevas versiones del siglo XX. Digilec-Revista internacional de lenguas y culturas, 2, 1-20. DOI 10.17979/ digilec.2015.2.0.1894

González, V. (2006). El río que se secaba los jueves (y otros cuentos imposibles). Anaya.
Huidobro, N. (2008). Los cuentos del abuelo Florián (o cuatro fábulas al revés). Everest. Jerez, I. \& Hernández L. (2015). La literatura infantil y el sistema social de representación de ideas: el caso de las fábulas y los cuentos de James Finn Garner. ENSAYOS, Revista de la Facultad de Educación de Albacete, 30 (2). http://www.revista.uclm.es/index. php/ensayos.

La Fontaine, J. (1768). Fables choisies, mises en vers par Monsieur de La Fontaine. Compagnie des Libraires.

Lanuza Hurtado, E. de (1979). El sabio rey loco y otros cuentos. La Galera.

Mcara, C. \& Calvin, D. (Eds.) (2011). Anti-Tales: The Uses of Disenchantment. Cambridge Scholars Publishing.

Mendoza Fillola, A. (1996). El intertexto lector: un análisis desde la perspectiva de la enseñanza de la literatura. Signa. Revista de la asociación española de semiótica, 5, 265-288.

Millé \&t Giménez, J. (1928): La fábula de La lechera a través de diversas literaturas. En Millé y Giménez, J. Estudios sobre literatura española, (pp. 1-35). Facultad de Humanidades y Ciencia de La Plata.

Müller, M. (1870). La migración de las fábulas. Conferencia impartida en The Royal Institution. Publicada en Müller, M. (1881). Chips from a German Workshop, Vol. IV, (pp. 139-198). Charles Scribner's Sons.

Noia Campos, C. (2010). Catálogo tipolóxico do conto galego de tradición oral. Clasificación, antoloxía e bibliografía. Universidad de Vigo.

Ozaeta, M. ${ }^{a}$ R. (2001). Traducciones y adaptaciones en castellano de las fábulas de La Fontaine en castellano en el siglo XX. En Lafarga, F. y Domínguez, A. Los clásicos franceses en la España del siglo XX. Estudios de traducción y recepción, (pp. 163-173). PPU. 
Pacheco, M. Á. (1988). La otra fábula de: La lechera. Mondadori.

Pérez Parejo, R. \& Soto Vázquez, J. (2015). ¿Educación frente a cultura? El problema de adaptación de cuentos tradicionales desde la Didáctica de la Literatura. Revista española de pedagogía, 262, 483-498.

Piña, C. (2013). La incidencia de la posmodernidad en las formas actuales de narrar. Cuadernos del CILHA, 14(2), 16-37.

Rodari, G. (1993). Cuentos por teléfono. Editorial Juventud.

Samaniego, F. M. (2003). Fábulas en verso castellano para uso del Real Seminario Vascongado, ed. Emilio Palacios.
Biblioteca virtual Miguel de Cervantes. http://www.cervantesvirtual.com/nd/ ark:/59851/bmc7s7j7.

Serrano, M. A. (2004). Caminos de la fábula. Antología. Ediciones Colihue.

Shiru, C. Et Calle, R. (Recop.). (1996). 101 cuentos clásicos de la China. Edaf-Arca de Sabiduría.

Szpunberg, A. (2006). Fábulas. Leer, jugar y aprender. El cuento de la lechera. Editorial Sol 90.

Ulwencreutz, L. (Ed.) (2015). Collected Swedish Foltales. Ulwencreutz Media. 
